\title{
A high prevalence of extreme hyperferritinemia in acute hepatitis patients
}

This article was published in the following Dove Press journal:

Hepatic Medicine: Evidence and Research

I I September 2009

Number of times this article has been viewed

\section{Kazuhiro Kotoh \\ Akihiro Ueda \\ Masatake Tanaka \\ Masayuki Miyazaki \\ Masaki Kato \\ Motoyuki Kohjima \\ Munechika Enjoji \\ Makoto Nakamuta \\ Ryoichi Takayanagi \\ Department of Medicine and Bioregulatory Science, Graduate School of Medical Science, Kyushu University, Fukuoda, Japan}

Correspondence: Kazuhiro Kotoh Department of Medicine and Bioregulatory Science, Graduate School of Medical Science, Kyushu University, 3-I-I Maidashi, Higashi-ku, Fukuoka 8I2-8582, Japan

$\mathrm{Tel}+81926425282$

Fax +8I 926425287

Email kotoh-k@intmed3.med.kyushu-u.ac.jp
Abstract: Although the mechanism underlying acute liver failure (ALF) has not been clarified, recent reports indicate overactivation of macrophages is involved in its progression. In diseases in which activated macrophages participate in the progression, elevated serum ferritin concentration counts among the characteristic laboratory findings. If activated macrophages play a key role in the development of ALF, serum ferritin levels might reflect the severity of acute liver injury. To confirm this, we evaluated the correlation between the serum ferritin concentration and other laboratory measurements in patients with acute hepatitis including ALF. One hundred consecutive patients with acute liver injury were enrolled, of whom 19 fulfilled the criteria for ALF. Serum ferritin concentrations correlated with serum alanine transferase activity as a whole. Interestingly, the correlation was strong in patients infected by hepatitis viruses, but weak in others. Although most patients with ALF had high levels of serum ferritin, not a few patients without ALF showed similar results. The serum ferritin level was generally increased in acute hepatitis patients, probably reflecting the degree of macrophage activation in the liver. Overactivation of macrophages appears to be essential, but not sufficient, for the development of ALF.

Keywords: acute hepatitis, acute liver failure, ferritin, macrophage

\section{Introduction}

Acute hepatitis is generally a transient, self-limiting disease regardless of the etiology. The severity of the disease is variable, and in some patients it proceeds to a fatal form, acute liver failure (ALF). Once a patient develops ALF, only liver transplantation (LT) is a promising treatment. ${ }^{1}$ Despite the poor prognosis, it is still impossible to distinguish patients likely to proceed to ALF from those of self-limiting course at an early stage of the disease because the mechanism underlying ALF has not been clarified.

Recently, several authors have described that the levels of products derived from activated macrophages, such as CD-163 and osteopontine, are increased in the serum from patients with ALF, indicating that overactivation of macrophages in liver might play a key role in the progression of ALF. ${ }^{2-4}$ However, the levels of the reported macrophage-derived materials are difficult to measure in ordinary laboratories.

On the other hand, it has been proven that overactivation of macrophages is crucial for the development of other diseases, including hemophagocytic lymphohistiocytosis (HLH) and macrophage-activation syndrome (MAS). ${ }^{5,6}$ Both involve elevated levels of serum ferritin, which is regarded to be secreted by activated macrophages ${ }^{6,7}$ If activated macrophages are involved in the progression of ALF, it is expected that serum ferritin concentration would be increased in patients with ALF compared with those with submit your manuscript | www.dovepress.con

Dovepress 
self-limiting acute hepatitis. Furthermore, it is easy to measure serum ferritin concentration in a hospital laboratory.

In the past, several authors have investigated the serum ferritin concentrations of patients with acute hepatitis. ${ }^{8-13}$ However, these studies were mainly focused on iron overload in the liver, and did not investigate a possible relation to activated macrophages. In this study, aiming to evaluate the serum ferritin concentrations in patients with various severities of hepatitis, including ALF, we enrolled consecutive patients who were admitted to our hospital suffering from acute hepatitis regardless of their clinical symptoms such as jaundice, encephalopathy and bleeding tendency. If we could show a significant increase in serum ferritin concentration in patients with ALF, it might support the hypothesis that macrophage activation is an essential step for its progression.

\section{Patients and methods}

\section{Patients}

This study was started on April 2005, and 118 patients suffering from acute hepatitis who were admitted to Kyushu University Hospital before June 2008 were evaluated. In this study, we defined acute hepatitis as an acute liver injury with elevated serum alanine aminotransferase (ALT) activity more than 10 times the normal upper limit (35 U/L). Those proven to have a history of chronic hepatitis ( 12 patients) and alcohol abuse (4 patients) were excluded from this study. All patients were tested for hepatitis virus A (HAV), hepatitis virus $\mathrm{B}(\mathrm{HBV})$, hepatitis virus $\mathrm{C}(\mathrm{HCV})$, Epstein-Barr virus, cytomegalovirus, herpes simplex virus, anti-nuclear antibody, immunoglobulins and urine copper concentration, in addition to ordinary laboratory tests. The serum ferritin concentrations were measured by chemiluminescent enzyme immunoassay system using the 7500 Clinical Analyzer (Hitachi High-Technologies Corporation, Tokyo, Japan). When a patient was suspected to be suffering from HLH, lumbar examination was performed. Two patients who fulfilled the criteria of HLH were excluded. Finally, 100 patients were enrolled in this analysis.

The patients consisted of 65 males and 35 females, with ages ranging from 17 to 93 years old. The etiology of liver injury varied: nine with HAV, 31 with HBV, three with $\mathrm{HCV}$, six owing to drugs other than acetaminophen, five with Wilson's disease, three with autoimmune hepatitis, and 43 with indeterminate causes. For patients with undetermined etiology, a serum test for hepatitis E virus was added, which revealed that none was positive.

When we defined ALF as acute hepatitis accompanied by hepatic encephalopathy more than grade 2 and prolonged prothrombin time (PT) international normalized ratio (PT-INR) more than 1.5, 19 fulfilled the criteria at admission.

The onset date of the disease was determined by a careful interview with the patient or family members in cases where the patients had developed encephalopathy. The symptoms at onset of the disease were general fatigue (62 patients), fever (27), jaundice (14), nausea or epigastralgia (12), appetite loss (7) and common cold-like symptoms (7); in some cases patients showed a mixture of two or three symptoms at onset. None of the enrolled patients fulfilled the criteria of sepsis or disseminated intravascular coagulation at admission.

After admission, plasma exchange was performed when hepatic encephalopathy was greater than grade 2 or prolonged downhill PT activity was observed. During hospitalization, 57 patients underwent plasma exchange.

Among the enrolled patients, five underwent LT and recovered without complications except one who died from liver failure. Of the other 95 patients, 84 survived with conservative treatment and 11 died.

\section{Statistical analysis}

The baseline characteristics of the patients on admission are shown as means \pm standard deviation (SD) for quantitative measurements. The distribution of each quantitative variable was checked using cumulative probability plots. Differences between patients with and without ALF were analyzed by means of a Wilcoxon rank sum test for quantitative variables, and the Fisher exact test for qualitative variables. To confirm their influence on the development of ALF, factors potentially associated with the severity of acute hepatitis were analyzed by univariate logistic analysis against the occurrence of ALF, which was followed by multivariate logistic regression analysis using stepwise variable selection. Factors with a $\mathrm{P}$ value $>0.10$ were removed from the multivariate analysis.

\section{Results}

In this study, the whole analysis was performed using only the findings on admission, ignoring the data and clinical courses after hospitalization, because the varied supportive treatment would have modified the immune response in the liver. Therefore, the patients with ALF described below were diagnosed based on the findings at admission, and those who developed ALF during hospitalization were not counted.

The serum ferritin concentrations on admission varied from $45 \mathrm{ng} / \mathrm{mL}$ to $876,790 \mathrm{ng} / \mathrm{mL}$, which showed a continuous log-normal distribution (Figure 1). The average 

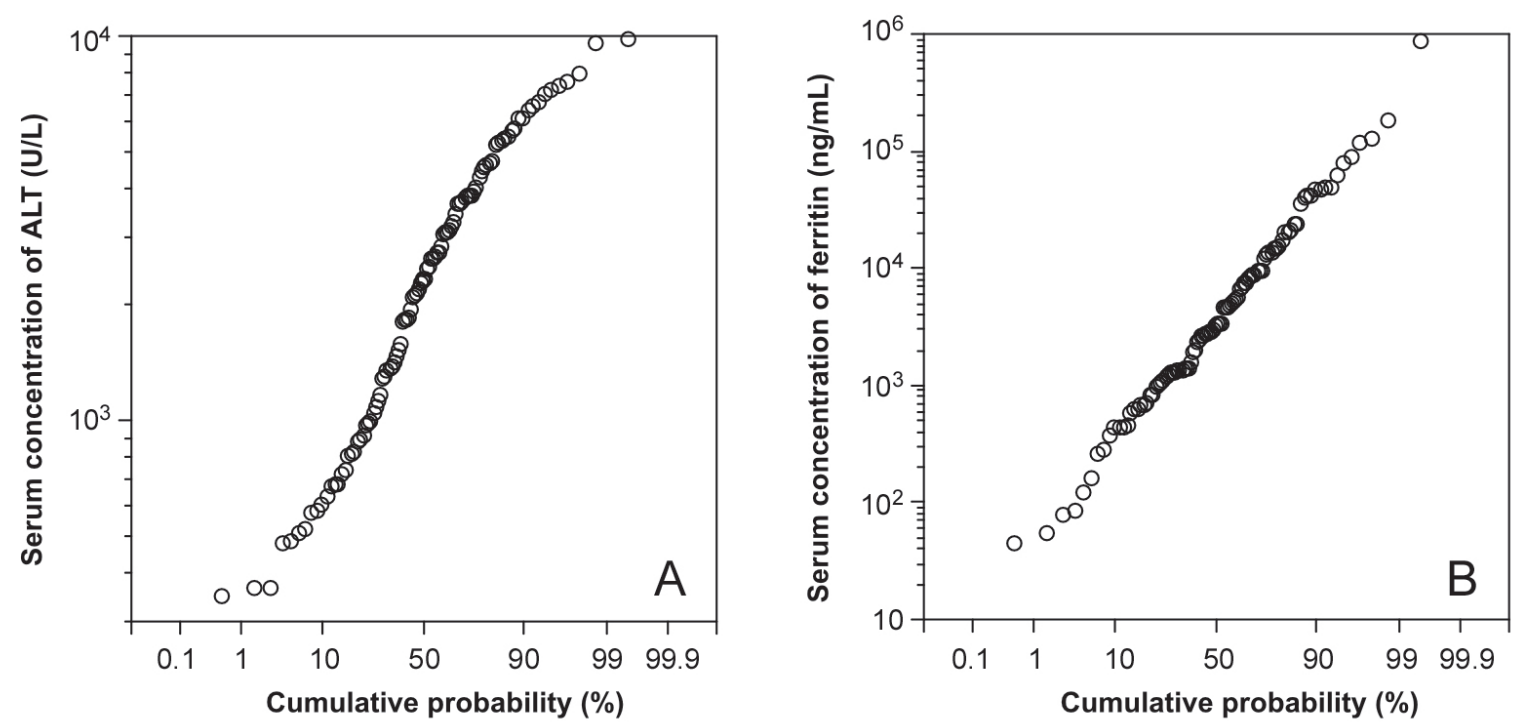

Figure I The distribution of serum alanine aminotransferase (ALT) activities (A) and serum ferritin concentrations (B) shown using a cumulative probability plot. The horizontal scale is plotted according to a Gaussian distribution, and the vertical scale is logarithmic. Both variables showed a log-normal distribution.

for all patients was $23,462.7 \mathrm{ng} / \mathrm{mL}$, and 28 patients $(28 \%)$ showed levels higher than $10,000 \mathrm{ng} / \mathrm{mL}$.

As the measurements of serum ALT activity also showed a log-normal distribution, we evaluated the correlation between the logarithm serum ferritin levels and serum ALT activity. Although there were not a few exceptions, the serum ferritin concentration correlated with serum ALT activity on the whole. Even when limiting the analysis to patients admitted to our hospital within a week of onset, the correlation was not different from that using all patients (Figure 2).

By dividing the patients into two groups, patients in which ALF was caused by hepatitis viruses and those with other etiologies, we found a strong correlation between serum ferritin levels and ALT activity in the former, but a weak correlation in the latter (Figure 3).

Regarding iron metabolism, we examined the serum iron concentration because previous reports referring to serum
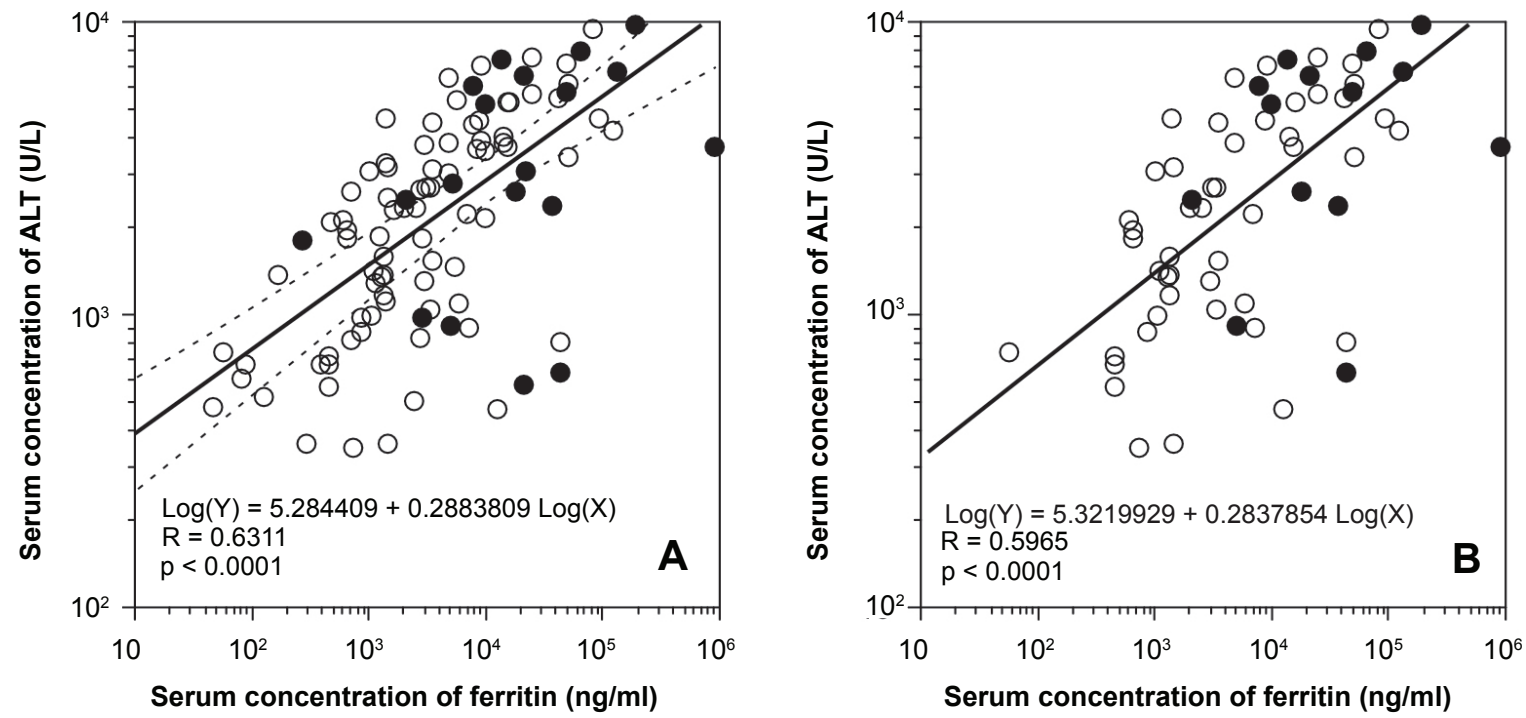

Figure $\mathbf{2}$ The serum ferritin concentration and the serum alanine aminotransferase (ALT) activity showed a significant correlation in calculations using the logarithmic values of the variables (A). Even when limiting the subjects to patients who were admitted to our hospital within a week of the onset of their symptoms, the correlation between these values were not different (B). Closed and open circles indicate patients with and without acute liver failure (ALF), respectively. 

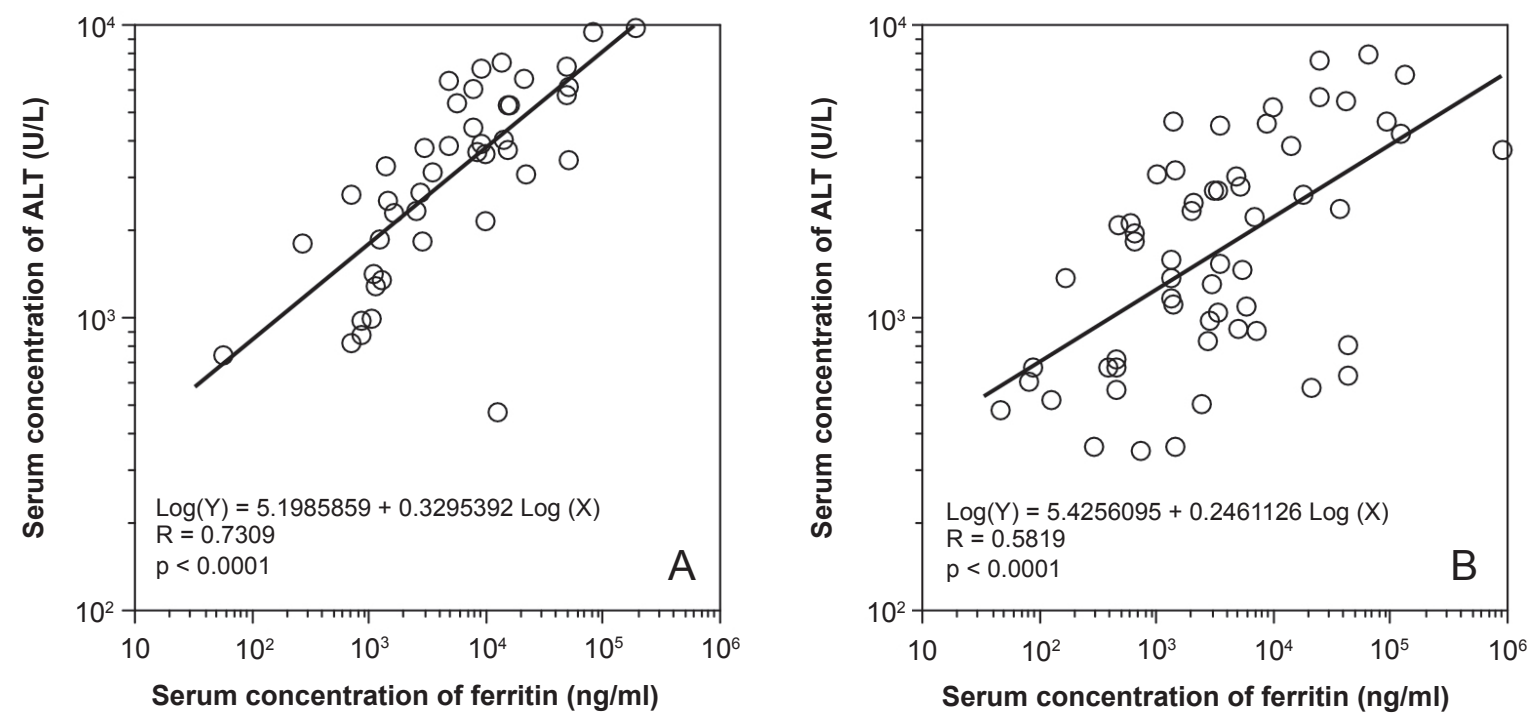

Figure 3 The correlation between the serum ferritin concentration and the serum alanine aminotransferase (ALT) activity was separately evaluated in patients in whom hepatitis was caused by hepatitis viruses $(\mathbf{A})$ and by other etiologies $(\mathbf{B})$ on admission. The two variables showed a strong correlation in the former, and a weak one in the latter.

ferritin levels in acute hepatitis patients mainly focused on iron overload. More than half patients (56\%) showed normal serum iron concentrations, regardless the elevation of serum ALT activity. Among the others, only four patients had serum iron concentrations more than twice the normal upper limit (male: $200 \mu \mathrm{g} / \mathrm{dL}$, female: $154 \mu \mathrm{g} / \mathrm{dL}$ ). No correlation was found between serum iron concentration and serum ALT activity.

On admission, 19 patients fulfilled the criteria for ALF. The differences in the characteristics on admission between patients with and without ALF are shown in Table 1. Naturally, the ALF group had higher serum ALT activities and serum ferritin concentrations than the others. However, this difference was more distinct for the comparison of serum ferritin concentrations (Figure 4). Similarly, in evaluating the correlation between PT-INR and serum ALT activity or ferritin concentration, although both serum ferritin level and ALT activity showed negative correlations with PT-INR, the latter was weaker than the former (Figure 5). These results seem to indicate that serum ferritin concentration more strongly influences the development of ALF than serum ALT activity.

To investigate whether laboratory variables, including serum ferritin levels and ALT activities, influence the progression of ALF, logistic analysis was performed using the data obtained on admission (Table 2). Although several variables, including $\log (\mathrm{ALT})$ and $\log$ (ferritin), showed a significant influence on ALF development, $\log$ (ferritin) had a more significant large odds ratio than other measures. Stepwise multiple regression analysis was performed using variables with $\mathrm{p}$-values $\leq 0.1$, which revealed that $\log$ (ferritin), serum albumin concentration and platelet count were independent prognostic factors (Table 3).

\section{Discussion}

In this study, we demonstrated that most of our patients with acute hepatitis had hyperferritinemia. We suppose that the increased serum ferritin levels should be mainly derived from activated macrophages in liver, but it is necessary to evaluate the possibility that at least some of the increase is derived from degenerated hepatocytes, as earlier investigators indicated. ${ }^{11,12}$ Our view concerning the origin of the increased ferritin in acute hepatitis is based on the following findings. First, although a positive correlation between serum ferritin concentration and ALT activity was observed, this correlation was not strong. Not a few patients showed high ALT activity and low ferritin concentration simultaneously. If the increased serum ferritin was mainly derived from hepatocytes, such exceptions could not be explained. Second, the serum iron concentration stayed within normal limits in more than half of the patients, and showed no correlation with serum ALT activity. Third, the degree of elevation of serum ferritin was remarkable. Out of the enrolled 100 patients, 28 had serum ferritin concentrations of more than $10,000 \mathrm{ng} / \mathrm{mL}$, and nine had levels over $50,000 \mathrm{ng} / \mathrm{mL}$. Such an extreme elevation of serum ferritin was comparable with data from patients with HLH or MAS, 
Table I Characteristics of patients on admission and their outcomes

\begin{tabular}{|c|c|c|c|}
\hline & With ALF & Without ALF & Total \\
\hline $\operatorname{Sex}(M / F)$ & $10 / 9$ & $55 / 26$ & $65 / 35$ \\
\hline Age* & $52.5 \pm 14.8$ & $43.5 \pm 17.1$ & $45.2 \pm 17.0$ \\
\hline PT-INR** & $4.91 \pm 4.48$ & $1.67 \pm 0.86$ & $2.29 \pm 2.43$ \\
\hline AST $(\mathrm{U} / \mathrm{L}) * *$ & $6330.3 \pm 4894.2$ & $2888.4 \pm 3136.8$ & $3542.4 \pm 3761.3$ \\
\hline ALT $(\mathrm{U} / \mathrm{L})^{*}$ & $4|I 0.1 \pm 280| .7$ & $2680.0 \pm 2028.2$ & $2951.7 \pm 2251.5$ \\
\hline Ferritin $(\mathrm{ng} / \mathrm{mL})^{* *}$ & $79588.7 \pm 198958.1$ & $10297.3 \pm 20826.0$ & $23462.7 \pm 91071.5$ \\
\hline $\mathrm{LDH}(\mathrm{U} / \mathrm{L})^{* *}$ & $4404.9 \pm 4626.7$ & $1823.0 \pm 2790.2$ & $2313.6 \pm 3349.5$ \\
\hline Albumin $(\mathrm{g} / \mathrm{dL})^{* *}$ & $3.4 \pm 0.4$ & $3.8 \pm 0.5$ & $3.7 \pm 0.5$ \\
\hline T Bilirubin (mg/dL) & $8.1 \pm 7.6$ & $6.4 \pm 5.7$ & $6.7 \pm 6.1$ \\
\hline $\mathrm{D} / \mathrm{T}$ Bilirubin ratio & $0.66 \pm 0.05$ & $0.69 \pm 0.55$ & $0.68 \pm 0.49$ \\
\hline $\mathrm{Hb}(\mathrm{g} / \mathrm{dL})$ & $13.6 \pm 1.5$ & $14.4 \pm 1.8$ & $14.2 \pm 1.8$ \\
\hline $\mathrm{Fe}(\mu \mathrm{g} / \mathrm{ml})$ & $235.2 \pm 74.8$ & $187.9 \pm 179.8$ & $201.2 \pm 158.3$ \\
\hline Platelet $\left(\times 10^{4} / \mu \mathrm{l}\right)^{* *}$ & $11.4 \pm 5.1$ & $15.9 \pm 5.3$ & $|5| \pm 5.6$. \\
\hline $\begin{array}{l}\text { Etiology } \\
\text { (HAV/HBV/HCV/Others) }\end{array}$ & $2 / 5 / 0 / 12$ & $7 / 26 / 3 / 45$ & $9 / 31 / 3 / 57$ \\
\hline $\begin{array}{l}\text { Encephalopathy**** } \\
\text { (none/grade I/II/III/IV) }\end{array}$ & $0 / 0 / 8 / 10 / 1$ & $76 / 5 / 0 / 0 / 0$ & $76 / 5 / 8 / 10 / 1$ \\
\hline Duration to admission (days) & $7.9 \pm 7.6$ & $8.6 \pm 6.6$ & $8.4 \pm 6.8$ \\
\hline $\begin{array}{l}\text { Outcome** } \\
\text { (LT/death without LT/alive without LT) }\end{array}$ & $|/ 7 /| \mid$ & $4 / 4 / 73$ & $5 / I 1 / 84$ \\
\hline
\end{tabular}

Notes: Asterisks on variables show significant differences between patients with and without ALF; ${ }^{*} \mathrm{p}<0.05 ;{ }^{* *} \mathrm{p}<0.01$; ***p $<0.00$ I; Duration to admission is the number of days from the onset of symptoms to admission.

Abbreviations: ALF, acute liver failure; $A L T$, alanine aminotransferase; $A S T$, aspartate aminotransferase; $H A V$, hepatitis $A$ virus; $H B V$, hepatitis $B$ virus; $H C V$, hepatitis $C$ virus; $\mathrm{LDH}$, lactate dehydrogenase; liver transplant; PT-INR, prothrombin time - international normalized ratio.
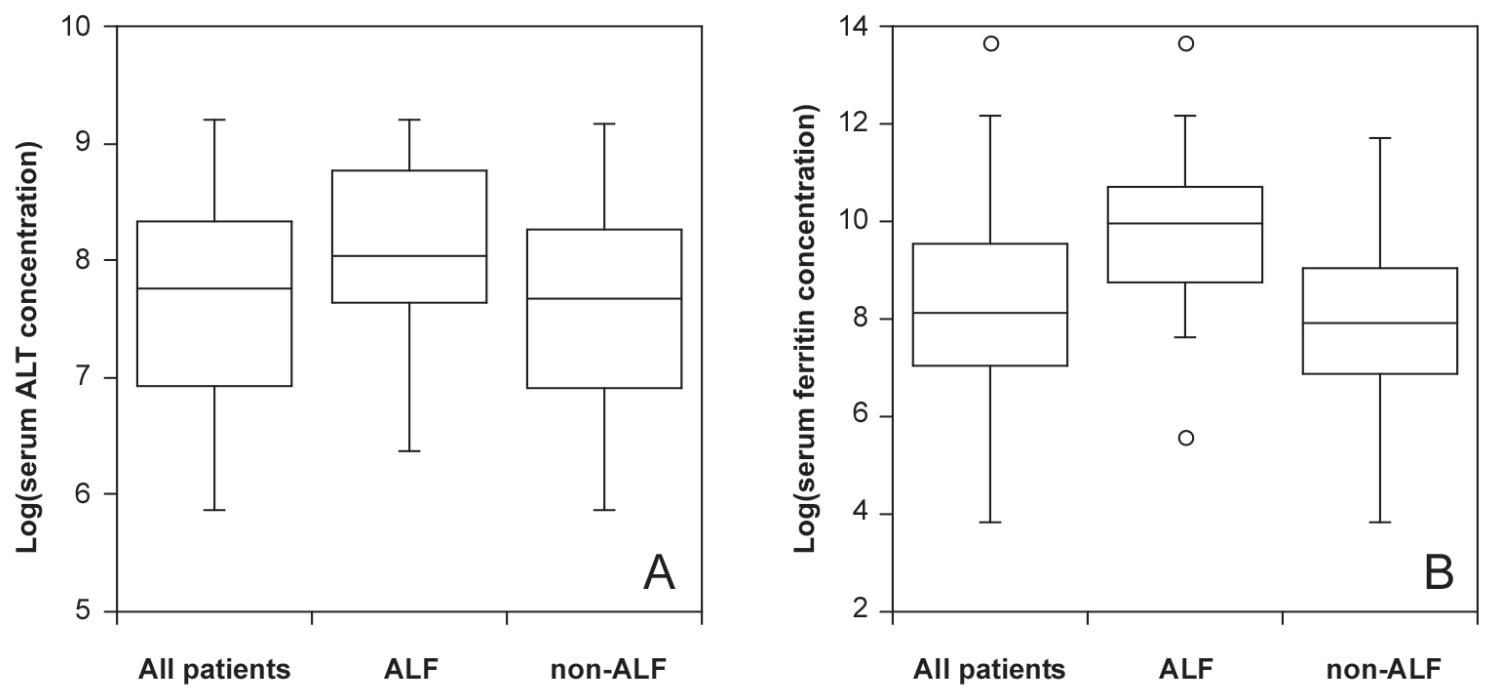

Figure 4 The distributions of serum ferritin concentrations (A) and serum alanine aminotransferase (ALT) activities (B) are shown using boxplots. Although the patients who fulfilled the criteria for acute liver failure (ALF) had significantly higher measurements than other patients, the difference was more distinct for the comparison of serum ferritin concentrations. 

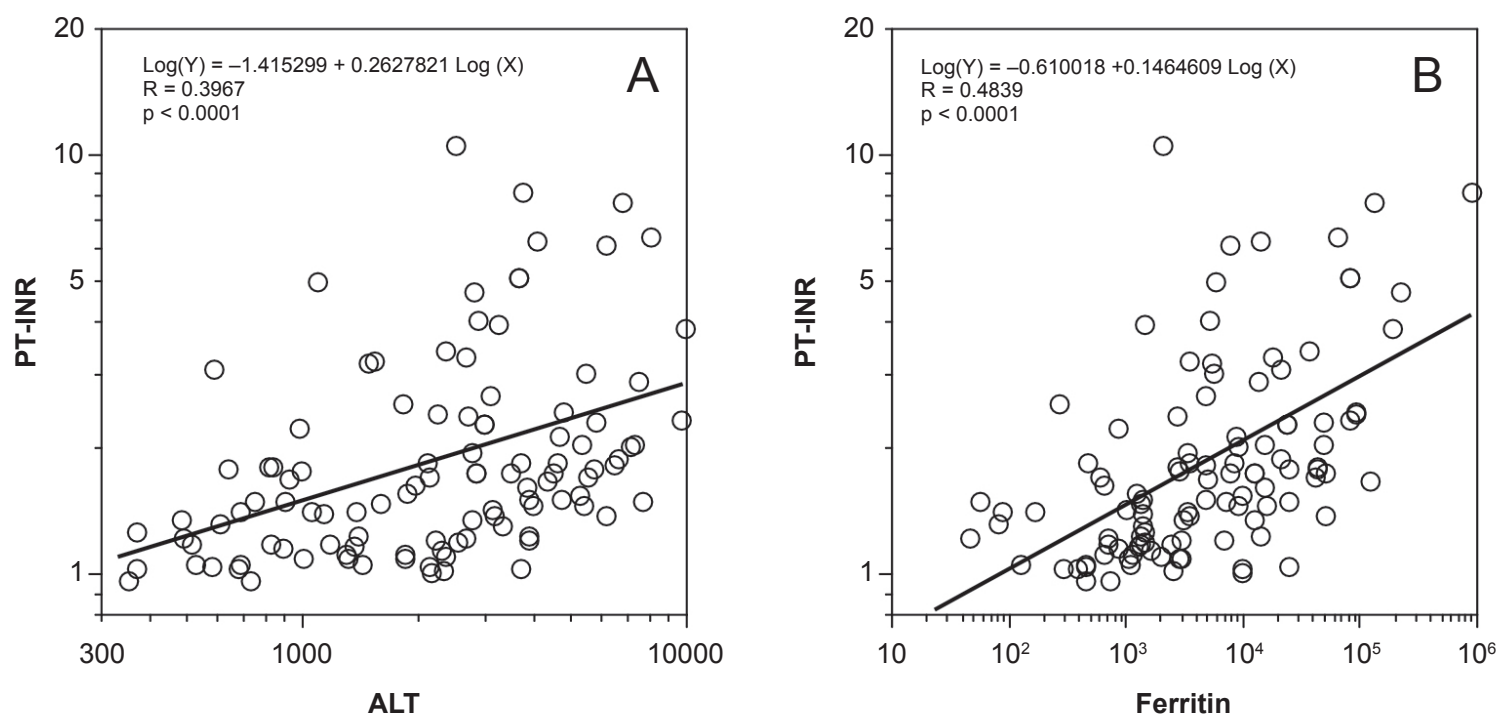

Figure $\mathbf{5}$ The influence of serum ferritin concentration and serum alanine aminotransferase (ALT) activity toward prothrombin time-international normalized ratio (PT-INR) was evaluated. Although both showed a significant correlation with PT-INR, the coefficient between the serum ferritin concentration and PT-INR was stronger.

in both of which activated macrophages are involved in the progression. Considering recent reports revealing that most patients with ALF have significantly high levels of macrophage-derived materials in their serum, the increased serum ferritin levels observed in our study are likely to be a product of intrahepatic activated macrophages..$^{2-4}$ However, additional strict examinations are required to confirm the origin of the increased serum ferritin. The comparison between serum ferritin concentration and the other materials derived from activated macrophages, such as soluble CD-163, might be helpful.

We started this study aiming to confirm whether serum ferritin concentrations are significantly increased in patients with ALF, reflecting macrophage activation in liver as well as other macrophage-derived materials. As shown in Table 1, the serum ferritin concentrations in patients with ALF were significantly higher than those of the others. We also demonstrated that the odds ratio for serum ferritin concentration against ALF occurrence was high compared with other variables using logistic analysis. These results seem to indicate that macrophage overactivation in liver contributes to the progression of ALF. However, from a different point of view, the dot plots revealed that a lot of patients who did not fulfill the ALF criteria had similar serum ferritin levels and ALT activities to those of patients diagnosed as having ALF. Furthermore, most patients with acute hepatitis had

Table 2 Univariate logistic analysis of acute liver failure occurrence on admission

\begin{tabular}{|c|c|c|c|c|c|}
\hline Variables & Estimate & $\mathbf{p}$ & Lower $95 \%$ & Upper 95\% & Odds ratio \\
\hline $\log ($ ferritin$)$ & 0.6417 & 0.0004 & 0.3168 & 1.0285 & 562.4 \\
\hline $\log (A L T)$ & 0.6616 & 0.0484 & 0.0367 & 1.3664 & 9.1 \\
\hline $\log (\mathrm{LDH})$ & 0.7124 & 0.0015 & 0.2842 & I.I757 & 22.4 \\
\hline Age & 0.0312 & 0.0408 & 0.0018 & 0.0623 & 10.7181 \\
\hline Albumin & -1.3617 & 0.0078 & -2.4229 & -0.3923 & 0.0332 \\
\hline T. Bilirubin & 0.0412 & 0.2785 & -0.0376 & 0.1156 & 3.879 \\
\hline $\mathrm{D} / \mathrm{T}$ ratio & -0.1453 & 0.8248 & -2.9416 & 0.8387 & 0.4942 \\
\hline Platelet & -0.1685 & 0.0025 & $-0.287 \mid$ & -0.0657 & 0.01338 \\
\hline $\mathrm{Hb}$ & -0.2420 & 0.0920 & -0.5344 & 0.03627 & 0.1310 \\
\hline Duration to admission & -0.0140 & 0.7233 & -0.0999 & 0.0585 & $0.666 I$ \\
\hline
\end{tabular}

Note: Duration to admission is the number of days from the onset of symptoms to admission.

Abbreviations: ALT, alanine aminotransferase; D/T ratio: Direct bilirubin/total bilirubin ratio; LDH, lactate dehydrogenase. 
Table 3 Multivariate logistic regression analysis using stepwise variable selection

\begin{tabular}{lclccc}
\hline Variables & Estimate & $\mathbf{p}$ & Lower 95\% & Upper 95\% & Odds ratio \\
\hline $\log$ (ferritin) & 0.7594 & 0.0008 & 0.3615 & 1.2737 & 1797.8219 \\
Albumin & -1.7839 & 0.0111 & -3.2972 & -0.4945 & 0.0116 \\
Platelet & -0.1209 & 0.0682 & -0.2580 & 0.0059 & 0.0453 \\
\hline
\end{tabular}

hyperferritinemia correlating to the serum levels of ALT, regardless of whether they fulfilled the ALF criteria, which indicates that macrophage activation is a common phenomenon in severe acute hepatitis. Therefore, from our results, we can infer that macrophage activation is indeed an important step for acute hepatitis to become severe, but not a deciding factor in the development of ALF. We should seek additional conditions that determine the progression of ALF.

To approach this problem, we should pay attention to the fact that the correlations between serum ALT activity and serum ferritin concentration were apparently different according to the etiology. We found that the correlation between them was strong in patients with hepatitis caused by hepatitis viruses, while it was weak in the others, which indicates that there are at least two different pathways to developing severe hepatitis. One mainly involves activated macrophages, and the other progresses without macrophage participation. Without considering the pathways separately, it seems impossible to determine the additional factors that finally drive patients with acute hepatitis into ALF.

For the pathway involving macrophage overactivation, we assume that one of the factors contributing to the development of ALF is its duration. In HLH or MAS, the progression is thought to result from patients being unable to control the hyperinflammatory response of the immune system, including natural killer cells, cytotoxic-T cells and macrophages. ${ }^{5}$ As these diseases are associated with extreme hyperferritinemia as well as acute severe hepatitis, a similar mechanism might be involved in the progression of ALF. Accepting this hypothesis, a transient hyperinflammatory response would result in self-limiting acute hepatitis, and a prolonged and uncontrolled response would lead to ALF.

On the other hand, in the pathway that progresses without macrophage activation, serum ferritin concentration is expected to remain low level in spite of the elevation of serum ALT activity. We assume that direct hepatotoxic materials such as halothane would be representative causes in this pathway, and the degree of resultant severity would be dose-dependent. There were some patients who showed only slight elevation of serum ferritin concentration whereas they had high ALT activity and prolonged PT even in the group with hepatitis viruses. We speculate that a violent attack of CTL on hepatocytes would have occurred in such cases, which could cause massive liver necrosis without the step of microcirculation disturbance.

In conclusion, we showed a high prevalence of hyperferritinemia in acute hepatitis patients, which indicates that macrophage overactivation would be involved in most patients with the disease. In such a pathway, serum ferritin concentration would strongly correlate with serum ALT activity. The patients who develop ALF had higher serum ferritin concentrations than the others. However, considering that there were patients who did not fulfill the ALF criteria, despite having laboratory examination results similar to those of ALF patients, a transient activation of macrophages in liver seems to be an insufficient condition to develop ALF.

\section{Disclosure}

The authors report no conflicts of interest in this work.

\section{References}

1. Sass DA, Shakil AO. Fulminant hepatic failure. Liver Transpl. 2005; 11:594-605.

2. Matsui A, Mochida S, Ohno A, Nagoshi S, Hirose T, Fujiwara K. Plasma osteopontin levels in patients with fulminant hepatitis. Hepatol Res. 2004;29(4):202-6.

3. Hiraoka A, Horiike N, Akbar SM, Michitaka K, Matsuyama T, Onji M. Soluble CD163 in patients with liver diseases: very high levels of soluble CD163 in patients with fulminant hepatic failure. $J$ Gastroenterol. 2005;40:52-6.

4. Møller HJ, Grønbaek H, Schiødt FV, et al. Soluble CD163 from activated macrophages predicts mortality in acute liver failure. J Hepatol. 2007;47:671-6.

5. Janka GE. Hemophagocytic syndromes. Blood Rev. 2007;21:245-53.

6. Ravelli A. Macrophage activation syndrome. Curr Opin Rheumatol. 2002;14:548-52.

7. Allen CE, Yu X, Kozinetz CA, McClain KL. Highly elevated ferritin levels and the diagnosis of hemophagocytic lymphohistiocytosis Pediatr Blood Cancer. 2008;50:1227-35.

8. Prieto J, Barry M, Sherlock S. Serum ferritin in patients with iron overload and with acute and chronic liver diseases. Gastroenterology. 1975;68:525-33.

9. Eastham EJ, Bell JI, Douglas AP. Serum ferritin levels in acute hepatocellular damage from paracetamol overdosage. $\mathrm{Br}$ Med $J$. 1976;1:750-1.

10. Hengeveld P, Zuyderhoudt FM. Iron mobilisation with chelating agents during acute viral hepatitis. Hepatogastroenterology. $1982 ; 29: 191-4$ 
11. Hengeveld P, Zuyderhoudt FM, Jobsis AC, van Gool J. Some aspects of iron metabolism during acute viral hepatitis. Hepatogastroenterology. 1982;29:138-41.

12. Milman N, Graudal N. Serum ferritin in acute viral hepatitis. Scand J Gastroenterol. 1984;19:38-40.
13. Triadou P, Regnat-Lusinchi A, Girot R. Use of the ferritin/alanine aspartate transaminase ratio as an iron overload marker independent of liver cell damage. Eur J Haematol. 1989;43:423-7.

\section{Publish your work in this journal}

Hepatic Medicine: Evidence and Research is an international, peerreviewed, open access journal covering all aspects of adult and pediatric hepatology in the clinic and laboratory including the following topics: Pathology, pathophysiology of hepatic disease; Investigation and treatment of hepatic disease; Pharmacology of drugs used for the treatment of hepatic disease. Issues of patient safety and quality of care will also be considered. The manuscript management system is completely online and includes a very quick and fair peer-review system, which is all easy to use. Visit http://www.dovepress.com/ testimonials.php to read real quotes from published authors.

Submit your manuscript here: http://www.dovepress.com/hepatic-medicine-evidence-and-research-journal 